\title{
The Efficiency of Telemedicine to Optimize Metabolic Control in Patients with Type 1 Diabetes Mellitus: Telemed Study
}

\author{
Enric Esmatjes, MD, PhD, Margarida Jansà, RN, Daria Roca, RN, Natalia Pérez-Ferre, MD, \\ Laura del Valle, RD, ${ }^{2}$ Sergio Martínez-Hervás, MD, PhD, ${ }^{3}$ Marisol Ruiz de Adana, MD, \\ Francisca Linares, MD, ${ }^{4}$ Ricardo Batanero, MD, ${ }_{1}^{5}$ Federico Vázquez, MD, $\mathrm{PhD}_{1}^{5}$ \\ Ramon Gomis, MD, PhD, and Oriol de Solà-Morales, MD, PhD, \\ for the Telemed-Diabetes Group
}

\begin{abstract}
Objective: This study evaluated the impact of an Internet-based telematic system on the economic and clinical management of patients with type 1 diabetes mellitus.

Research Design and Methods: This 6-month prospective, randomized, comparative, open, multicenter study included patients with type 1 diabetes $>18$ years old treated with multiple insulin doses and with a glycated hemoglobin $\left(\mathrm{HbA}_{1 \mathrm{c}}\right)$ level of $>8 \%$. We compared an intervention group (IG) (two face-to-face and five telematic appointments) with a control group (CG) (seven face-to-face appointments). The variables studied were (1) patient and healthcare team costs, (2) metabolic control, (3) knowledge of diabetes, (4) quality of life, and (5) self-care treatment adherence.

Results: Of the 154 patients included, 118 (76.6\%) completed the study (IG, 54; CG, 64). The time used by the $\mathrm{CG}$ to follow the program was $823 \pm 645 \mathrm{~min}$ versus $353 \pm 222 \mathrm{~min}$ in the IG $(P<0.0001)$. Compared with the CG, the IG required less healthcare time from the professionals $(288 \pm 105 \mathrm{~min}$ vs. $232 \pm 89 \mathrm{~min} ; P<0.001)$. $\mathrm{HbA}_{1 \mathrm{c}}$ improved in both groups (IG, $9.2 \pm 1.5 \%$ [77.0 $\left.\pm 17.0 \mathrm{mmol} / \mathrm{mol}\right] \mathrm{vs} .8 .7 \pm 1.5 \%[71.6 \pm 17.0 \mathrm{mmol} / \mathrm{mol}]$ $[P<0.001] ; \mathrm{CG}, 9.2 \pm 0.9 \%[77.0 \pm 10.0 \mathrm{mmol} / \mathrm{mol}] \mathrm{vs} .8 .6 \pm 0.9 \%[70.5 \pm 10.0 \mathrm{mmol} / \mathrm{mol}][P<0.001]$, as $\mathrm{did}$ knowledge and self-care treatment adherence.

Conclusions: The use of interactive telematic appointments in subjects with type 1 diabetes and inadequate metabolic control is an efficient strategy, providing results comparable to those of face-to-face appointments in relation to improvement in glycemic control, knowledge acquisition, and self-care treatment adherence, with a significant reduction in the time used, especially by patients.
\end{abstract}

\footnotetext{
${ }^{1}$ Diabetes Unit, Hospital Clinic, University of Barcelona, Biomedical Research Center in Diabetes and Associated Metabolic Disorders, Barcelona, Spain.

${ }^{2}$ Endocrinology and Nutrition Unit, San Carlos Hospital Clinic, Biomedical Research Center in Diabetes and Associated Metabolic Disorders, Madrid, Spain.

${ }^{3}$ Endocrinology Unit, University Hospital Clinic, University of Valencia, Biomedical Research Center in Diabetes and Associated Metabolic Disorders, Valencia, Spain.

${ }^{4}$ Endocrinology Unit, Carlos Haya University Hospital, Biomedical Research Center in Diabetes and Associated Metabolic Disorders, Málaga, Spain.

${ }^{5}$ Endocrinology Unit, Cruces University Hospital, University of the Basque Country, Biomedical Research Center in Diabetes and Associated Metabolic Disorders, Barakaldo, Spain.

${ }^{6}$ August Pi i Sunyer Institute of Biomedical Studies, Hospital Clinic, University of Barcelona, Biomedical Research Center in Diabetes and Associated Metabolic Disorders, Barcelona, Spain.

${ }^{7}$ Health Institute Technology Transfer, Pere Virgili Institute of Health Studies, Barcelona, Tarragona, Spain.

This study is registered at ClinicalTrials.gov with clinical trial registration number NCT 01337141.

Part of this article was presented at the $49^{\text {th }}$ EASD Congress, held in Barcelona, Spain, September 23-27, 2013.
} 


\section{Introduction}

$\mathbf{T}$ IGHT GLYCEMIC CONTROL and intensive support are essential for the prevention of acute events and the minimization of long-term complications in type 1 diabetes. ${ }^{1-3}$ In order to achieve this objective, a clinical visit is recommended every 3 months, ${ }^{4}$ after having received adequate diabetes self-management education. However, as patients are progressively leading a more complex and integrated professional lifestyle and because of the current shortage of professional and economic resources, this is not always possible in real practice. Thus, the challenge is to find alternative methods to monitor metabolic control within the context of an overstressed healthcare system.

Because self-management and computer-aided algorithms still seem to remain far from widespread implementation, 5,6 telemedicine intervention in diabetes and providing monitoring (including educational and therapeutic services) could be a possible alternative to face-to-face outpatient appointments. $^{7-10}$ Recently, several devices have incorporated through interfaces allowing more comprehensive management of the data for both the patient and the physician. ${ }^{11}$ Such advances have been reported to improve fitting insulin needs to supply, but the effectiveness of such devices has yet to be tested. ${ }^{12}$ As these data become more available, new patientphysician communication channels are being tested. Nonetheless, it must be determined whether these new technologies provide benefits in glucose management, resource saving, or both. ${ }^{13}$ Therefore, it is crucial to determine the costeffectiveness of this alternative. ${ }^{14}$ Along this line, it is important to point out that no favorable impact on glycated hemoglobin $\left(\mathrm{HbA}_{1 \mathrm{c}}\right)$ has been described to date in any study ${ }^{15,16}$ and that the data related to costs, albeit positive, are very scarce and limited to single-center studies. ${ }^{17,18}$ There are few multicenter studies, ${ }^{19}$ and some have not shown any savings. ${ }^{20}$

In this context, the objective of this study was to estimate the impact on costs of an Internet-based telemedicine system replacing clinic visits in a program designed to improve metabolic control in patients with type 1 diabetes.

\section{Research Design and Methods}

\section{Participants}

The inclusion criteria included having been diagnosed with type 1 diabetes at least 5 years previously, 18-55 years of age, multiple insulin doses, poor glycemic control with $\mathrm{HbA}_{1 \mathrm{c}}$ level of $>8 \%$, performing an average of at least three blood glucose tests per day, and having Internet access at home. The exclusion criteria included any contraindication to tight glycemic control, plans to become pregnant or pregnancy, psychiatric disorders, and lack of appointment compliance. All the patients provided written informed consent, and the Ethics Committee of each participating hospital approved the study.

\section{Trial design and procedures}

We performed a randomized 6-month, open-label, parallelgroup study involving five hospitals in Spain. Prior to the trial, a blinded computer-based nonclustered (by center) prespecified randomization list was created. After inclusion of subjects, physicians allocated patients to either group after calling a centralized number. Patients were invited to partici- pate on attending routine clinical outpatient appointments. Eligible participants were evaluated in order to ensure adequate diabetes self-management education. On the first visit (V1) the patients were electronically randomized to either the control group (CG) or the intervention group (IG). The patients in the IG were trained in the telematic system. The program included six monthly visits (V2-V7) in both groups. In the IG five visits were telematic, and the last visit (V7) was in the hospital setting. In the CG all the visits were at the hospital. Participants were asked to carry out at least three self-monitoring of blood glucose tests per day, using the same meter (Glucocard $^{\mathrm{TM}} \mathrm{G}+$ meter; provided by Menarini Diagnostics, Firenze, Italy). In both groups blood glucose control, insulin doses, mild hypoglycemia (in the last 2 weeks), and severe hypoglycemia (in the last 6 months) were evaluated in order to define the most appropriate times of blood glucose monitoring, optimization of basal and short-acting insulin doses, and adjustment of insulin with food and physical activity. At every visit, patients were asked to recall if they needed extra medical/ paramedical interventions, and details were obtained on the time and costs of each visit.

Patients allocated to the IG were instructed in the management of the Medical Guard Diabetes ${ }^{\circledR}$ (MGD) system (Pulso Ediciones, Barcelona, Spain) and were asked to report the data once a month. A response from their diabetes team was then expected within the following 3 days with recommendations on treatment adjustments. Access to the MGD system was granted at the time of randomization.

Data from the CG were obtained on-site during the visit and were then transferred to an electronic database, whereas subjects in the IG filled in a predefined electronic questionnaire. Investigators could know whether patients had completed the questionnaires and send reminders when needed.

\section{MGD system}

The MGD system is an Internet-based telemedicine system that allows automatic downloading of the self-monitoring of blood glucose values to a secure Web site (www.medicalguard.net) where the data are available to investigators at any time. Additionally, the patient may introduce changes in the insulin doses, diet, or exercise, as well as make comments in a text message of $<500$ words. The MGD is a system compatible with several meters (those from Abbott Laboratories [Abbott Park, IL], Bayer Hispania SL [Barcelona], Johnson \& Johnson SA [Zug, Switzerland], and Menarini Diagnostics SA). The system has different types of presentations of glucose values, including the standard day, linear graph, histogram, and .pdf report. In addition, the insulin and carbohydrate schedule could be seen.

Patients in the IG were provided with an interface PCmeter and the specific software.

\section{Outcome measures}

Costs. To analyze the patient costs per each type of telematic or hospital appointment, we determined the overall time spent in each visit, the direct transport payments, and the need for extra visits (or telephone consultations). On each clinical or telematic appointment, patients and professionals were asked to answer a specifically designed costs questionnaire. The medical team costs included time spent on both types of appointments. 
The time costs for patients were also accounted for considering the time devoted to each visit (home-based or hospitalbased) and adjusted for professional role and job category (unemployed, household workers, students, noncertified service workers, certified workers, bachelors degree, or other). According to the Spanish Instituto Nacional de Estadistica, time-cost adjustments were made considering the average national salary (for Spain in 2012) for each of the categories described. Similar to other studies, ${ }^{17}$ in the time costs for healthcare professionals we attributed $75 \%$ of the time consumed to the nurse and $25 \%$ to the physician (with the average nurse's wage $=24 € / \mathrm{h}$ and the average doctor's wage $=48 € / \mathrm{h}$ ). For transportation costs, we took the mean value of the different ranges provided in the per-visit questionnaires.

Extra visits were also recorded, and if needed, a cost of $120 €$ per visit was considered, according to the tariffs of the Spanish Health System.

Clinical evolution. The effectiveness of the intervention was monitored by $\mathrm{HbA}_{1 \mathrm{c}}$ as well as the number of hypoglycemia events (mild or severe), acute complications of diabetes, and adherence to treatment. After glycemia charts were reviewed, a comprehensive clinical evaluation was performed at each visit to assess changes in diet and insulin regimens. $\mathrm{HbA}_{1 \mathrm{c}}$ was measured by high-performance liquid chromatography (Menarini Diagnostics).

1. Hypoglycemia. Hypoglycemic episodes were obtained from logbooks and the memory of the glucose meters. Mild events were defined as signs or symptoms associated with hypoglycemia experienced by the patient and self-treated without the need for assistance from a third party or a blood glucose level of $<3.3 \mathrm{mmol} / \mathrm{L}$. Severe hypoglycemic events (those associated with neuroglycopenia severe enough to require treatment from a third party) and severe hyperglycemic events (requiring medical consultation) and ketoacidosis were considered as the number of events per patient during the study.

2. Quality of life. Quality of life was measured by the disease-specific Spanish Diabetes Quality of Life test, which has four scales: satisfaction (minimum score 15, maximum score 75), impact (minimum score 17, maximum score 85 ), social worry (minimum score 7 , maximum score 35 ), and diabetes worry (minimum score 4, maximum score 20), with a lower score indicating better perception $^{21,22}$ and with the generic visual analog scale of the European Quality of Life test. ${ }^{23}$

3. Diabetes self-management. Diabetes self-management was evaluated by blood glucose testing frequency, and insulin modification was determined from the logbooks and the meter downloads for each patient, as well as the Diabetes Knowledge Questionnaire ${ }^{24}$ adapted to Spanish, adherence to self-care with the Diabetes Self-Care Inventory-Revised, ${ }^{25}$ and hypoglycemia perception with the Clarke test. ${ }^{26}$

\section{Power calculation and statistical analysis}

The study was powered to detect a cost change in the IG $(\beta=0.05, \alpha=0.05)$. To detect a $20 \%$ difference in the costs at 6 months, 72 patients were needed in each group to achieve a statistical power of $95 \%$ with a $5 \%$ two-sided $\alpha$ level. ${ }^{17,18} \mathrm{We}$ aimed to recruit 154 patients, allowing for a $10 \%$ dropout rate (STATA version 11; StataCorp, College Station, TX).

Data are expressed as mean \pm SD values or as a percentage. Changes from baseline values at the end of the study were compared with a paired $t$ test. The mean values were compared using the $t$ test for paired and nonpaired variables, assuming, according to Altman and Bland, ${ }^{27}$ that the boundaries between parametric and rank methods are not clear. A $P$ value of $<0.05$ was considered statistically significant. All statistical calculations were performed with Statistical Package for Social Science (SPSS) for personal computers version 21.0.0 software (SPSS, Inc., Chicago, IL).

\section{Results}

\section{Patient population}

In total, 162 patients were invited to participate, 154 of whom were subsequently assessed and randomized from May 2011 to October 2011. Seventy-eight patients were assigned to the IG, and 76 were allocated to the CG. There were no remarkable differences at baseline between the two groups in regard to demographic and clinical characteristics (Table 1). After 6 months of follow-up, 36 patients had dropped out of the study (24 in the IG and 12 in CG, with a statistical power of $85 \%$ remaining) because of noncompliance with the protocol, connection problems, accident, or suicide attempt (Fig. 1). At 2, 4, and 6 months, there were eight, two, and two patients lost to follow-up in the CG and 15 , seven, and two in the IG, respectively. There were no differences in the baseline characteristics of the patients who dropped out of the study.

\section{Costs}

In relation to patients who finished the study, the mean total time spent by the patients in the IG in the follow-up

Table 1. Demographic and Baseline Characteristics OF A RANDOMIZED SAMPLE $(N=154)$

\begin{tabular}{|c|c|c|c|}
\hline & $\begin{array}{l}\text { Control } \\
\text { group }\end{array}$ & $\begin{array}{l}\text { Intervention } \\
\text { group }\end{array}$ & $\mathrm{P}$ value \\
\hline \multirow{2}{*}{\multicolumn{4}{|c|}{ Baseline $\mathrm{HbA}_{1 \mathrm{c}}$}} \\
\hline & & & \\
\hline $\begin{array}{l}\% \\
\mathrm{mmol} / \mathrm{mol}\end{array}$ & $\begin{array}{c}9.2 \pm 0.9 \\
77 \pm 13.6\end{array}$ & $\begin{array}{r}9.3 \pm 1.5 \\
78 \pm 7.1\end{array}$ & 0.372 \\
\hline Age (years) & $31.5 \pm 9.0$ & $32.2 \pm 10.1$ & 0.650 \\
\hline Female sex $(\%)$ & 52.6 & 57.6 & 0.269 \\
\hline BMI $\left(\mathrm{kg} / \mathrm{m}^{2}\right)$ & $24.9 \pm 4.3$ & $25.6 \pm 4.1$ & 0.348 \\
\hline Weight (kg) & $75.1 \pm 17.6$ & $71.5 \pm 14.3$ & 0.063 \\
\hline $\begin{array}{l}\text { Duration of diabetes } \\
\text { (years) }\end{array}$ & $16.6 \pm 8.4$ & $17.7 \pm 9.1$ & 0.473 \\
\hline SMBG (per week) & $26.5 \pm 8.8$ & $25.3 \pm 8.8$ & 0.388 \\
\hline Insulin (IU/kg/day) & $0.7 \pm 0.2$ & $0.8 \pm 0.2$ & 0.001 \\
\hline Severe hypoglycemia ${ }^{a}$ & $0.4 \pm 1.0$ & $0.2 \pm 0.7$ & 0.170 \\
\hline Knowledge (DKQ2) & $24.7 \pm 4.1$ & $24.8 \pm 4.5$ & 0.926 \\
\hline Adherence (SCI-R) (\%) & $64.2 \pm 10.8$ & $60.0 \pm 11.7$ & 0.024 \\
\hline Quality of life (EuroQol) & $66.4 \pm 18.2$ & $63.0 \pm 18.5$ & 0.266 \\
\hline Clarke $\geq 4 \mathrm{R}(\%)$ & 28.9 & 18.7 & 0.240 \\
\hline
\end{tabular}

Data are mean \pm SD values.

${ }^{a}$ Last 6 months.

BMI, body mass index; DKQ2, Diabetes Knowledge Questionnaire; EuroQoL, European Quality of Life; $\mathrm{HbA}_{1 \mathrm{c}}$, glycated hemoglobin; SCI-R, Diabetes Self-Care Inventory-Revised; SMBG, self-monitoring of blood glucose. 


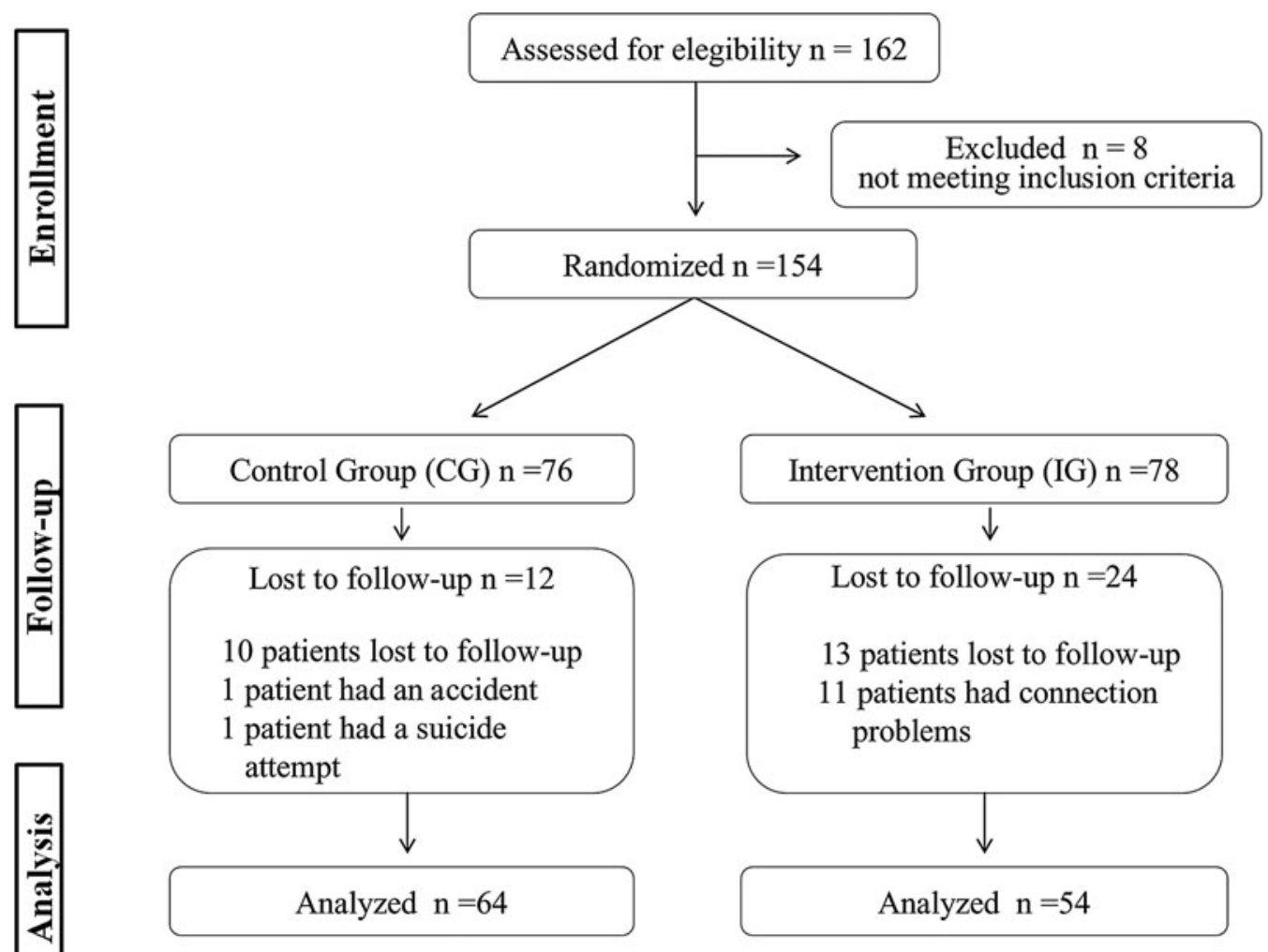

FIG. 1. Study flowchart.

visits (V2-V6) was $20 \mathrm{~min}$ (range, 14-22 min), versus $117 \mathrm{~min}$ (range, 112-119 min) in the CG (including travel time). The total time of the program in the CG was $823 \pm 645$ min versus $353 \pm 222 \mathrm{~min}$ in the IG $(P<0.0001)$.

The percentages of unemployed, household workers, students, noncertified service workers, certified workers, bachelor's degrees, or other in the CG were $6.2 \%, 4.5 \%, 21.5 \%$, $15.4 \%, 27.7 \%, 23.0 \%$, and $1.5 \%$, respectively, with similar data in the IG $(3.8 \%, 3.8 \%, 18.9 \%, 13.2 \%, 28.3 \%, 26.4 \%$, and $5.7 \%$ ). Consequently, according to the salaries of the Spanish population, the mean estimated cost of the total clinical visits for patient was 38-116€ in the IG and 90-270€ in the CG. The mean transportation cost was $6.3 \pm 5.2 €$ in the IG and $32.1 \pm 30.0 €$ in the CG $(P<0.0001)$. The cost of the modem and cable was $10 €$ per month and patient.

The diabetes team costs in the length of appointments of the total program were lower in the IG $(288 \pm 105 \mathrm{~min}$ vs. $232 \pm 89$ min; $P<0.001$ ), with means of $185.6 €$ and $144 €$, respectively.

In relation to diabetes management, during the follow-up only two patients in the CG needed an extra visit because of sustained hyperglycemia. The number of telephone consultations per patient during the study was 0.54 in the IG and 0.30 in the $\mathrm{CG}$.

\section{Clinical evolution}

At the end of the study we observed a similar reduction of $\mathrm{HbA}_{1 \mathrm{c}}$ levels in both groups: IG, 9.2 $\pm 1.5 \%(77.0 \pm$ $17.0 \mathrm{mmol} / \mathrm{mol})$ versus $8.7 \pm 1.5 \%(71.6 \pm 17.0 \mathrm{mmol} / \mathrm{mol})$ $(P<0.001) ; \mathrm{CG}, 9.2 \pm 0.9 \%(77.0 \pm 10.0 \mathrm{mmol} / \mathrm{mol})$ versus
$8.6 \pm 0.9 \%(70.5 \pm 10.0 \mathrm{mmol} / \mathrm{mol})(P<0.001)$. Eight patients in the IG and six patients in the CG achieved $\mathrm{HbA}_{1 \mathrm{c}} \leq 7.5 \%$. Only one patient in the CG achieved a level of HbA1c $<7 \%$. No patient presented with ketoacidosis during the study. The numbers of severe and mild hypoglycemic episodes were similar in both groups. Mild hypoglycemia increased slightly during the study (Table 2). We found a significant increase in the knowledge test Diabetes Knowledge Questionnaire scores and in the adherence to self-care in both groups. After 6 months of follow-up we did not observe differences in the IG in relation to quality of life, whereas improvement was observed in two scales of the Diabetes Quality of Life (Satisfaction and Diabetes Worry) in the CG (Table 2).

There was a tendency to increase the number of selfmonitoring of blood glucose tests per week, both in the IG (V1 vs. V7, $25.8 \pm 8.5$ vs. $28.5 \pm 7.9 ; P=0.133$ ) and in the $C G$ (V1 vs. V7, $26.3 \pm 7.7$ vs. $28.8 \pm 7.1 ; P=0.006$ ).

\section{Discussion}

To our knowledge this is the first prospective, randomized controlled study to evaluate the cost of telematic care as a replacement to face-to-face outpatient appointments in a specifically designed intensive follow-up program in poorly controlled type 1 diabetes patients. The application of this telematic tool for intensive monitoring of these patients is less costly and more efficient than on-site visits. After a 6month follow-up, the results related to improvement in metabolic control were within the range compared with patients following on-site visits. 
Table 2. Clinical Evolution (Results Per-Protocol)

\begin{tabular}{|c|c|c|c|c|c|c|c|c|}
\hline & \multicolumn{4}{|c|}{ Control group } & \multicolumn{4}{|c|}{ Intervention group } \\
\hline & $\mathrm{n}$ & Visit 1 & Visit 7 & $\mathrm{P}$ value & $\mathrm{n}$ & Visit 1 & Visit 7 & $\mathrm{P}$ value \\
\hline $\mathrm{HbA}_{1 \mathrm{c}}$ & 64 & & & & 54 & & & \\
\hline$\%$ & & $9.2 \pm 0.9$ & $8.6 \pm 0.9$ & $<0.001$ & & $9.2 \pm 1.5$ & $8.7 \pm 1.5$ & $<0.001$ \\
\hline $\mathrm{mmol} / \mathrm{mol}$ & & $77.0 \pm 10.0$ & $70.5 \pm 10.0$ & & & $77.0 \pm 17.0$ & $71.6 \pm 17.0$ & \\
\hline Weight (kg) & 64 & $71.8 \pm 14.4$ & $73.0 \pm 14.9$ & 0.002 & 53 & $75.5 \pm 17.6$ & $75.8 \pm 17.7$ & 0.453 \\
\hline $\operatorname{BMI}\left(\mathrm{kg} / \mathrm{m}^{2}\right)$ & 64 & $25.2 \pm 4.5$ & $25.7 \pm 4.7$ & $<0.001$ & 53 & $26.0 \pm 4.4$ & $26.2 \pm 4.4$ & 0.539 \\
\hline Insulin (U/kg/day) & 63 & $0.6 \pm 0.2$ & $0.7 \pm 0.3$ & 0.508 & 53 & $0.9 \pm 0.3$ & $0.9 \pm 0.3$ & 0.411 \\
\hline Mild hypoglycemia ${ }^{a}$ & 58 & $4.1 \pm 3.8$ & $7.6 \pm 4.3$ & $<0.001$ & 48 & $4.0 \pm 3.5$ & $6.7 \pm 5.6$ & $<0.001$ \\
\hline Severe hypoglycemia ${ }^{b}$ & 55 & $0.5 \pm 1.1$ & $0.2 \pm 0.1$ & 0.002 & 46 & $0.2 \pm 0.6$ & $0.2 \pm 1.2$ & 0.733 \\
\hline Knowledge (DKQ2) ${ }^{\mathrm{c}}$ & 63 & $24.8 \pm 4.4$ & $26.8 \pm 4.0$ & $<0.001$ & 51 & $24.5 \pm 4.6$ & $26.1 \pm 4.6$ & 0.008 \\
\hline Adherence (SCI-R) $(\%)^{\mathrm{c}}$ & 63 & $64.1 \pm 10.7$ & $69.8 \pm 9.6$ & $<0.001$ & 53 & $61.3 \pm 12.0$ & $66.1 \pm 11.0$ & 0.003 \\
\hline Quality of life (EuroQol) ${ }^{\mathrm{c}}$ & 50 & $67.1 \pm 17.7$ & $66.9 \pm 17.4$ & 0.922 & 50 & $65.0 \pm 18.8$ & $69.9 \pm 18.7$ & 0.904 \\
\hline $\mathrm{DQoL}^{\mathrm{C}}$ & 63 & & & & 53 & & & \\
\hline Satisfaction & & $35.6 \pm 10.0$ & $33.2 \pm 9.0$ & 0.021 & & $35.1 \pm 10.4$ & $34.5 \pm 8.9$ & 0.561 \\
\hline Impact & & $33.9 \pm 8.4$ & $33.5 \pm 8.4$ & 0.554 & & $34.1 \pm 8.4$ & $32.3 \pm 7.8$ & 0.061 \\
\hline Social Worry & & $14.3 \pm 5.3$ & $14.2 \pm 4.9$ & 0.928 & & $13.7 \pm 5.0$ & $13.6 \pm 4.6$ & 0.868 \\
\hline Diabetes Worry & & $9.8 \pm 3.3$ & $9.0 \pm 3.0$ & 0.011 & & $8.9 \pm 3.0$ & $8.8 \pm 3.0$ & 0.742 \\
\hline Clarke $\geq 4 \mathrm{R}(\%)^{\mathrm{c}}$ & 63 & 30.8 & 23.8 & 0.317 & 53 & 17.3 & 17.0 & 1.000 \\
\hline
\end{tabular}

Data are mean \pm SD values.

${ }^{\mathrm{a}}$ Last 2 weeks.

${ }^{\mathrm{b}}$ Last 6 months.

${ }^{\mathrm{c}}$ Validated questionnaires.

BMI, body mass index; DKQ2, Diabetes Knowledge Questionnaire; DQoL, Diabetes Quality of Life; EuroQoL, European Quality of Life; $\mathrm{HbA}_{1 \mathrm{c}}$, glycated hemoglobin; SCI-R, Diabetes Self-Care Inventory-Revised; SMBG, self-monitoring of blood glucose.

The most relevant finding in this study was the time saved by the telematic care users. Accordingly, the patients in the IG spent an average of $6 \mathrm{~h}$ to complete the follow-up (including five telematic and two hospital visits), whereas those in the CG required an average of $14 \mathrm{~h}$ to complete the face-to-face followup. An average of approximately $20 \%$ less time was spent by the diabetes team in the total follow-up of the IG compared with the CG. In addition to the time saved, subjects in the IG also spent less money on transportation than those in the CG.

From a clinical point of view we observed that the use of the telematic system was as useful as face-to-face visits in improving metabolic control (similar $\mathrm{HbA}_{1 \mathrm{c}}$ reduction in both groups, similar number of hypoglycemic events) in a group of patients with chronic bad control, mainly because of poor selfmanagement refractory to previous attempts to improve metabolic control. The aim of our therapeutic program in these patients, in which both groups received enhanced care compared with what is standardly provided in Spain, was to improve the knowledge and skills related to self-management. ${ }^{28}$ In this respect, it is important to point out that our telematic intervention showed a similar positive impact as the conventional visits. In addition, as previously shown, ${ }^{7}$ we observed that the adherence to self-care improved similarly in both groups of patients. On the other hand, it could be speculated that the loss of the conventional clinical visit, face-to-face with a healthcare professional, could induce deterioration in the patient's quality of life. However, this was not the case in our study, but rather the contrary was observed: patients became somewhat empowered to manage their disease.

It is important to note that the total cost of both interventions may be considered site-specific and that the generalizability of the results is limited. However, we believe this is not the case in the present study for several reasons: first, this was a multicenter clinical trial, including markedly different centers in Spain, in very different cities and related cost of living or availability of transportation (access to physician). Second, costs are derived mainly from the time spent for the visit, which may be different across different countries, but the difference (statistically significant) remained stable and constant. And lastly, a sensitivity analysis of all the cost figures is not likely to show any relevant change in either the results or the direction of the recommendation.

Our results agree with a previous report by Chase et al. ${ }^{17}$ in a study also performed in patients with type 1 diabetes. Thus, this trial clearly shows that telemedicine is effective and safe, less expensive, and more efficient than on-site visits. There is limited literature showing similar results. ${ }^{29,30}$ In fact, there is conflicting evidence on the effectiveness of telemedicine. ${ }^{18,20,30,31}$ This, however, may be due to incomplete implementation of technological advances and to studies being undertaken with a study period of an insufficient length to allow adequate evaluation. The population included in our trial mimics the "real world" population, and it is generally accepted that the participation in any clinical trial could improve metabolic control by the effect of more frequentation. Nonetheless, in the present study, we found similar improvements in a partially uncontrolled blinded population, thereby reinforcing the contention of a sustained effect of telemedicine across time beyond the trial bias.

This study has some limitations. The first is the relatively high number of dropouts in the IG due to technical problems. This is a key point in order to implement these technologies in clinical practice. Robust, easy systems are necessary. Second, there may be some biases in the costs evaluation. The results could be underestimated in relation to the ability of the patients to recall indirect costs derived from the visits (for example, substitutions in their usual activity) and because the cost attributable to accompanying persons was not quantified. 
To the contrary, we did not consider indirect hospital costs in the face-to-face visits. Moreover, there may be some costs unaccounted for such as the Internet connection, point of measurement costs, etc., which may be considered as negligible and with no analysis of the sensitivity of the cost variables. Furthermore, we have provided costs in both time and economic counter value, as we acknowledge there may be disparities in the costing figures when the project is to be applied in other constituencies (circumstances), although, as previously discussed, we would not anticipate any difference in the results.

And finally, we must acknowledge that in this trial we have accounted for the costs of the MGD interface. However, when patients were enrolled, they were asked to have an Internet connection, and currently several self-monitoring of blood glucose meters come with features that enable a similar control free of charge.

In conclusion, the application of telemedicine applied to control subjects with poorly controlled type 1 diabetes is a valid strategy, providing results similar to those of on-site visits on comparison of the improvement in glycemic control, the acquisition of knowledge, quality of life, and treatment adherence. This approach also significantly reduces the time and the costs involved, especially for the patients.

\section{Telemed-Diabetes Group Members}

The following investigators are members of the TelemedDiabetes Group: Anibal Aguayo, Ricardo Batanero, Luis Castaño, Sonia Gaztambide, and Federico Vázquez, Barakaldo, Spain; Enric Esmatjes, Ramón Gomis, Margarida Jansà, Daria Roca, Oriol Solà-Morales, and Mercè Vidal, Barcelona, Spain; Alfonso Calle, Mercedes Galindo, Natalia Pérez-Ferre, Laura del Valle, and Manuel Serrano-Ríos, Madrid, Spain; Federico Casimiro-Soriguer Federico, Marisol Ruiz de Adana, and Francisca Linares, Málaga, Spain; and Carmena Rafael and Sergio Martinez-Hervás, Valencia, Spain.

\section{Acknowledgments}

This work was supported by the Centro de Investigación Biomédica en Red de Diabetes y Enfermedades Metabólicas Asociadas (ISCIII, Ministerio de Ciencia e Innovación). We thank to Ferran Torres for statistical support. Devices, strips, and logbook for self-monitoring blood glucose were supported by Menarini Diagnostics, Firenze, Italy.

\section{Author Disclosure Statement}

No competing financial interests exist.

E.E. and R.G. oversaw the research and prepared the manuscript. O.deS.-M. contributed to study concept and design and assisted in the preparation of the manuscript. M.J. and D.R. conducted research and analyses and assisted in the preparation of the manuscript. N.P.-F., S.M.-H., M.R.deA., and F.V. conducted research and assisted in the preparation of the manuscript. R.B., L.delV., and F.L. conducted research.

\section{References}

1. The effect of intensive treatment of diabetes on the development of long-term complications in insulin-dependent diabetes mellitus. The Diabetes Control and Complications Trial Research Group. N Engl J Med 1993;329:977-986.
2. Nathan DM, Cleary PA, Backlund JY, Genuth SM, Lachin JM, Orchard TJ, Raskin P, Zinman B; Diabetes Control and Complications Trial/Epidemiology of Diabetes Interventions and Complications (DCCT/EDIC) Study Research Group: Intensive diabetes treatment and cardiovascular disease in patients with type 1 diabetes. N Engl J Med 2005;353:2643-2653.

3. The relationship of glycemic exposure $\left(\mathrm{HbA}_{1 \mathrm{c}}\right)$ to the risk of development and progression of retinopathy in the Diabetes Control and Complications Trial. Diabetes Control and Complications Trial (DCCT) Research Group. Diabetes 1995;44:968-983.

4. American Diabetes Association: Standards of medical care in diabetes-2013. Diabetes Care 2013;36(Suppl 1):S11-S66.

5. Klonoff DC, True MW: The missing element of telemedicine for diabetes: decision support software. J Diabetes Sci Technol 2009;3:996-1001.

6. Bellazzi R: Telemedicine and diabetes management: current challenges and future research directions. J Diabetes Sci Technol 2008;2:98-104.

7. Trief PM, Izquierdo R, Eimicke JP, Teresi JA, Goland R, Palmas W, Shea S, Weinstock RS: Adherence to diabetes self care for white, African-American and Hispanic American telemedicine participants: 5 year results from the IDEATel project. Ethn Health 2013;1:83-96.

8. Klonoff DC: Improved outcomes from diabetes monitoring: the benefits of better adherence, therapy adjustments, patient education, and telemedicine support. J Diabetes Sci Technol 2012;6:486-490.

9. Kouris I, Mougiakakou S, Scarnato L, Iliopoulou D, Diem P, Vazeou A, Koutsouris D: Mobile phone technologies and advanced data analysis towards the enhancement of diabetes self-management. Int J Electron Healthc 2010;5:386-402.

10. Davis RM, Hitch AD, Salaam MM, Herman WH, ZimmerGaller IE, Mayer-Davis EJ: TeleHealth improves diabetes self-management in an underserved community: diabetes telecare. Diabetes Care 2010;33:1712-1717.

11. Rossi MC, Nicolucci A, Di Bartolo P, Bruttomesso D, Girelli A, Ampudia FJ, Kerr D, Ceriello A, Mayor Cde L, Pellegrini F, Horwitz D, Vespasiani G: Diabetes Interactive Diary: a new telemedicine system enabling flexible diet and insulin therapy while improving quality of life: an openlabel, international, multicenter, randomized study. Diabetes Care 2010;33:109-115.

12. Siriwardena LS, Wickramasinghe WA, Perera KL, Marasinghe RB, Katulanda P, Hewapathirana R: A review of telemedicine interventions in diabetes care. J Telemed Telecare 2012;18:164-168.

13. Franc S, Daoudi A, Mounier S, Boucherie B, Dardari D, Laroye H, Neraud B, Requeda E, Canipel L, Charpentier G: Telemedicine and diabetes: achievements and prospects. Diabetes Metab 2011;37:463-476.

14. Farmer A, Gibson OJ, Tarassenko L, Neil A: A systematic review of telemedicine interventions to support blood glucose self-monitoring in diabetes. Diabet Med 2005;22: 1372-1378.

15. Marrero DG, Vandagriff JL, Kronz K, Fineberg NS, Golden MP, Gray D, Orr DP, Wright JC, Johnson NB: Using telecommunication technology to manage children with diabetes: the Computer-Linked Outpatient Clinic (CLOC) Study. Diabetes Educ 1995;21:313-319.

16. Nunn E, King B, Smart C, Anderson D: A randomized controlled trial of telephone calls to young patients with poorly controlled type 1 diabetes. Pediatr Diabetes 2006; 7 : 254-259. 
17. Chase HP, Pearson JA, Wightman C, Roberts MD, Oderberg AD, Garg SK: Modem transmission of glucose values reduces the costs and need for clinic visits. Diabetes Care 2003;26:1475-1479.

18. Jansà M, Vidal M, Viaplana J, Levy I, Conget I, Gomis R, Esmatjes E: Telecare in a structured therapeutic education programme addressed to patients with type 1 diabetes and poor metabolic control. Diabetes Res Clin Pract 2006; 74:26-32.

19. Charpentier G, Benhamou PY, Dardari D, Clergeot A, Franc S, Schaepelynck-Belicar P, Catargi B, Melki V, Chaillous L, Farret A, Bosson JL, Penfornis A; TeleDiab Study Group: The Diabeo software enabling individualized insulin dose adjustments combined with telemedicine support improves $\mathrm{HbA}_{1 \mathrm{C}}$ in poorly controlled type 1 diabetic patients: a 6-month, randomized, open-label, parallelgroup, multicenter trial (TeleDiab 1 Study). Diabetes Care 2011;34:533-539.

20. Moreno L, Dale SB, Chen AY, Magee CA: Costs to Medicare of the Informatics for Diabetes Education and Telemedicine (IDEATel) home telemedicine demonstration. Diabetes Care 2009;32:1202-1204.

21. Influence of intensive diabetes treatment on quality-of-life outcomes in the Diabetes Control and Complications Trial. Diabetes Care 1996;19:195-203.

22. Millan M, Reviriego J, Del Campo J: Reappraisal of the Spanish version of the Diabetes Quality of Life Questionaire (EsDQOL). Endocrinol Nutr 2002;49:322-324.

23. Badia X, Roset M, Montserrat S, Herdman M, Segura A: A description and its applications. European Quality of Life scale. Med Clin 1999;112(Suppl 1):79-85.

24. Lennon GM, Taylor KG, Debney L: Knowledge, attitudes, technical competence and blood glucose control of type 1 diabetic patients during and after an education programme. Diabet Med 1990;7:825-832.

25. Jansà M, Vidal M, Giménez M, Conget I, Galindo M, Roca D, Colungo C, Esmatjes E, Salamero M: Psychometric analysis of the Spanish and Catalan versions of the Dia- betes Self-Care Inventory-revised version questionnaire. Patient Prefer Adherence 2013;7:997-1005.

26. Weinger K, Butler HA, Welch GW, La Greca AM: A psychometric analysis of the Self-Care Inventory-revised with adults. Diabetes Care 2005;28:1346-1352.

27. Altman DG, Bland JM: Parametric v non-parametric methods for data analysis. BMJ 2009;338:a3167.

28. Clarke WL, Cox DJ, Gonder-Frederick LA, Julian D, Schlundt D, Polonsky W: Reduced awareness of hypoglycemia in adults with IDDM. A prospective study of hypoglycemic frequency and associated symptoms. Diabetes Care 1995; 18:517-522.

29. Franc S, Daoudi A, Mounier S, Boucherie B, Laroye H, Peschard C, Dardari D, Juy O, Requeda E, Canipel L, Charpentier G: Telemedicine: what more is needed for its integration in everyday life? Diabetes Metab 2011; 37(Suppl 4):S71-S77.

30. Montori VM, Helgemoe PK, Guyatt GH, Dean DS, Leung TW, Smith SA, Kudva YC: Telecare for patients with type 1 diabetes and inadequate glycemic control: a randomized controlled trial and meta-analysis. Diabetes Care 2004;27: 1088-1094.

31. Levin K, Madsen JR, Petersen I, Wanscher CE, Hangaard J: Telemedicine diabetes consultations are cost-effective, and effects on essential diabetes treatment parameters are similar to conventional treatment: 7-year results from the Svendborg Telemedicine Diabetes Project. J Diabetes Sci Technol 2013;7:587-595.

Address correspondence to: Enric Esmatjes, $M D, P h D$

Diabetes Unit

Institut Clinic de Malalties Digestives i Metabòliques Hospital Clínic

170 Villarroel Street 08036 Barcelona, Spain

E-mail: esmatjes@clinic.ub.es 